\title{
ANALISIS PRODUKSI ALAT BERAT TERHADAP PEKERJAAN GALIAN PADA PROYEK JALAN (SUMBERJO-PELITAKAN)
}

\author{
Okky Anwar1, Milawaty Waris,ST.,MT2, Nurmiati Zamad,ST.,MT3 \\ Teknik Sipil, Fakultas Teknik, Universitas Sulawesi Barat. Jln Baharuddin Lopa, Majene \\ Telp/Fax: (0422)22559, 2700559, Website: http://www.unsulbar.ac.id
}

\begin{abstract}
Heavy equipment production is the ability or maximum results achieved by a production tool in hours or days, where a large production capacity will accelerate and facilitate project completion, but conversely if the productivity of the tool is small then the work will be slow and not in accordance with the project completion plan. Earthwork (quarry) is a digging activity to obtain soil material from a location, the material is obtained by digging with an excavator with a depth and boundaries that have been agreed and determined then the volume of material transported by dumptruck and must be in accordance with the tub capacity of dumptruck.

The production of heavy equipment in research uses quantitative and qualitative methods. The results of the analysis of the calculation of the production of heavy equipment excavators obtained $17.58 \mathrm{~m}^{3} /$ per-hour, with a per-cycle production of $0.72 \mathrm{~m}^{3}$, and cycle time was used for one rotation for 54 seconds. While the largest volume of earth excavation in excavation works was $79.1 \mathrm{~m}^{3}$, the smallest volume of earth excavation was $53.7 \mathrm{~m}^{3}$. The dump truck heavy equipment obtained a cycle of 9.74 minutes with a cycle of $2.56 \mathrm{~m}^{3}$ with an hourly production of $6.46 \mathrm{~m}^{3}$. Costs incurred for the use of heavy equipment types of excavators and dump trucks for excavators each Rp. 8.005.270, - and a dump truck of $R p$. 8,322,554.
\end{abstract}

Keywords: Heavy equipment production, Heavy equipment operating costs

\begin{abstract}
Abstrak
Produksi alat berat adalah kemampuan atau hasil maksimal yang dicapai oleh suatu alat berproduksi dalam satuan jam atau hari, dimana kapasitas produksi yang besar akan mempercepat dan memperlancar penyelesaian proyek, namun sebaliknya apabila produktifitas alat kecil maka pekerjaan akan lambat dan tidak sesuai dengan rencana penyelesaian proyek. Pekerjaan galian tanah (quarry) adalah kegiatan menggali untuk memperoleh bahan material tanah dari sebuah lokasi, material diperoleh dengan cara menggali dengan alat excavator dengan kedalaman dan batas batas yang sudah di sepakati dan ditentukan kemudian volume material diangkut oleh dumptruck dan harus sesuai dengan kapasitas bak dari dumptruck.

Produksi alat berat dalam penelitian menggunakan metode kuantitatif dan kualitatif. Hasil analisa perhitungan produksi alat berat excavator diperoleh $17,58 \mathrm{~m}^{3} / \mathrm{per}$ jam, dengan produksi per-siklus sebesar $0,72 \mathrm{~m}^{3}$, dan waktu siklus digunakan satu putaran selama 54 detik. Sedangkan volume galian tanah yang terbesar pada pekerjaan galian sebesar $79,1 \mathrm{~m}^{3}$, volume galian tanah terkecil sebesar $53,7 \mathrm{~m}^{3}$. Alat berat dump truck diperoleh siklus 9,74 menit dengan persiklus sebanyak $2,56 \mathrm{~m}^{3}$ dengan produksi perjam sebanyak $6,46 \mathrm{~m}^{3}$. Biaya yang dikeluarkan untuk penggunaan alat berat jenis excavator dan dump truck masing-masing untuk excavator sebesar Rp. 8.005.270,- dan dump truck Rp. 8.322.554,-
\end{abstract}

Kata Kunci : Produksi alat berat, Biaya pengoperasian alat berat 


\section{PENDAHULUAN}

Pada pelaksanaan pekerjaan penentuan suatu komposisi peralatan yang tepat sangat penting, agar dapat beroperasi dan berproduksi seefektif mungkin. Untuk memperoleh metode kerja optimum maka diperlukan keserasian operasi dari setiap peralatan yang digunakan dan pengaturan medan yang baik sehingga bernilai ekonomis.

Pekerjaan tanah dalam suatu proyek jalan merupakan salah satu bagian yang sangat vital. Pekerjaan tanah disini yaitu pekerjaan galian, pada umumnya pekerjaan tanah dikerjakan dengan bantuan alat berat, tujuan dari penggunaan alat berat tersebut adalah untuk memudahkan manusia dalam mengerjakan pekerjaannya sehingga hasil yang diharapkan dapat tercapai dengan lebih mudah pada waktu yang relatif lebih singkat.

Setiap pekerjaan konstruksi terdapat beberapa tahap pekerjaan yang direncanakan dan dilaksanakan. Salah satu tahapan pekerjaan tersebut adalah pekerjaan tanah. Pekerjaan galian tanah (quarry) adalah kegiatan menggali untuk memperoleh bahan material tanah dari sebuah lokasi, material diperoleh dengan cara menggali dengan alat excavator dengan kedalaman dan batas batas yang sudah di sepakati dan ditentukan. Oleh karna itu alat berat yang digunakan pada suatu proyek harus sesuai dengan situasi dan kondisi proyek tersebut, ketepatan dalam memilih alat berat sangat mempengaruhi produktifitas alat tersebut.

Produktifitas alat berat adalah kemampuan atau hasil maksimal yang dicapai oleh suatu alat berproduksi dalam satuan jam atau hari, dimana kapasitas produksi yang besar akan mempercepat dan memperlancar penyelesaian proyek, namun sebaliknya apabila produktifitas alat kecil maka pekerjaan akan lambat dan tidak sesuai dengan rencana penyelesaian proyek. Namun dalam pengoperasian alat berat excavator banyak faktorfaktor yang mempengaruhi kapasitas produksi excavator, tentu dalam hal ini merugikan pemakai excavator tersebut.

\section{METODE}

\section{A. Jenis Penelitian}

Jenis penelitian yang dilakukan merupakan gabungan dari survey lapangan secara langsung dan studi literatur (perpustakaan) yaitu dengan cara mengumpulkan data - data yang berhubungan dengan tugas akhir ini yang bersumber dari buku serta referensi lainnya sebagai pendekatan teori maupun sebagai perbandingan untuk mengkaji peneltian.

\section{B. Lokasi dan Waktu Penelitian}

1. Lokasi

Lokasi penelitian ini dilaksanakan pada Ruas Sumberjo - Pelitakan Wonomulyo Kabupaten Polewali Mandar.

2. Waktu

Waktu penelitian dilaksanakan kurang lebih 2 bulan yang dimulai september - oktober 2018.

\section{Sumber Data}

Adapun data - data yang digunakan dalam penelitian ini adalah sebagai berikut :

1. Data Primer yang diperoleh dari lapangan/lokasi meliputi bagian kegiatan penggalian lokasi tersebut.
a. Data Lokasi
b. Data-data Alat Berat 
2. Data sekunder

Data sekunder,berupa data yang diperoleh dari referensi tertentu atau literatur-literatur yang berkaitan dengan alat berat.

\section{Tahap dan Jenis Pekerjaan}

Backhoelexcavator

Backhoelexcavator sering juga disebut pull shovel, adalah alat dari golongan shovel yang khusus dibuat untuk menggali material dibawah permukaan tanah atau dibawah tempat kedudukan alatnya. Galian di bawah permukaan ini misalnya parit, lubang untuk pondasi bangunan, lubang galian pipa dan sebagainya. Keuntungan backhoelexcavator ini ialah menggali sambil mengatur dalamnya galian yang lebih baik. Karena kekauan konstruksinya, backhoelexcavator ini lebih menguntungkan untuk penggalian dengan jarak dekat dan memuatkan hasil galian ke truk.

Tipe backhoelexcavator dibedakan dalam beberapa hal antara lain dari alat kendali dan undercarriage (bagian bawahnya).

Menurut alat kendali :

a. Dengan kendali kabel (cable controlled),

b. Dengan kendali hidrolis (hydraulic controlled). Menurut undercarriage-nya :

1) Roda rantai (crawler mounted),

2) Roda karet (wheel mounted).

Untuk mulai menggali dengan backhoelexcavator bucket dijulurkan ke depan ke tempat galian, bila bucket sudah pada posisi yang diinginkan lalu bucket diayun ke bawah seperti dicangkulkan, kemudian lengan bucket diputar ke arah alatnya. Setelah bucket terisi penuh lalu diangkat dari tempat penggalian dan dilakukan swing, dan pembuangan material hasil galian dapat dilakukan ke truk atau tempat yang lain.

\section{PEMBAHASAN}

\section{A. Pekerjaan Galian Tanah}

Pekerjaan galian tanah sebanyak 20 patok, patok 1 sampai patok 14 berada pada dusun Tulung Agung sedangkan patok 15 sampai patok 20 berada di dusun Pohayam Desa Sumberjo Kec. Wonomulyo, Hasil galian diperoleh volume total sebesar 453.2 $\mathrm{m}^{3}$, pada patok $\mathrm{P} 1$ total volume $74.8 \mathrm{~m}^{3}$ merupakan yang paling terbesar dengan panjang galian $226 \mathrm{~m}$, lebar $1,24 \mathrm{~m}$ dan kedalaman $0,13 \mathrm{~m}$ sedangkan pada patok P7 total volume yang di peroleh sebesar $2,47 \mathrm{~m}^{3}$ merupakan produksi yang terkecil dengan panjang galian pada patok tersebut hanya sepanjang $9 \mathrm{~m}$, lebar $1,2 \mathrm{~m}$. dan kedalaman $0,12 \mathrm{~m}$

Dari hasil perhitungan volume galian tanah pada pekerjaan jalan ruas sumberjo pelitakan di peroleh volume hasil galian di lapangan sebanyak $453.2 \mathrm{~m}^{3}$ dengan biaya pengoperasian Rp. 16.327.824 sedangkan target volume galian yang tercantum pada RAB perencanaan yaitu sebanyak $412.6 \mathrm{~m}^{3}$ dengan biaya Rp. 25.635 .770

Tabel 23 Produksi dan Penyelesaian Galian

\begin{tabular}{|c|c|c|c|}
\hline \multirow{2}{*}{ Hari Kerja } & Volume $\left(\mathrm{m}^{3}\right)$ & Panjang(m) & Waktu Penyelesaian (jam) \\
\hline 1 & 79.1 & 241.6 & 4.5 \\
\hline 2 & 49.2 & 155 & 4.8 \\
\hline 3 & 83.5 & 265 & 4.75 \\
\hline 4 & 73.1 & 220.8 & 4.16 \\
\hline 5 & 66.4 & 231 & 3.78 \\
\hline
\end{tabular}




\begin{tabular}{|l|l|l|l|}
\hline 6 & 42.5 & 131 & 2.42 \\
\hline 7 & 59.4 & 186 & 3.38 \\
\hline
\end{tabular}

\section{B. Biaya Pengoperasian Alat}

Biaya pengoperasian selama penggunaan alat berat excavator dan Dump Truck pada pekerjaan galian tanah dapat di lihat pada tabel 24 dan tabel 25 di bawah ini.

Tabel 24 Biaya Pengoperasian Excavator

\begin{tabular}{|l|l|c|}
\hline No & Uraian & Rp/jam \\
\hline 1 & Bahan bakar minyak (BBM) & 141.075 \\
2 & Pelumas(oli) & 7.197 \\
3 & Oli hidrolik & 12.152 \\
4 & Gemuk/gress & 19.040 \\
5 & Operator & 50.000 \\
6 & Pemeliharaan dan perawatan alat & 78.431 \\
\hline \multicolumn{2}{|l|}{ Biaya pengoperasian per jam } & 307.895 \\
\hline
\end{tabular}

Sumber : Analisis Biaya Pengoperasian Alat

Tabel 25 Biaya Pengoperasian Dump Truck

\begin{tabular}{|l|l|r|}
\hline No & \multicolumn{1}{|c|}{ Uraian } & \multicolumn{2}{|c|}{ Rp/jam } \\
\hline 1 & Bahan bakar minyak (BBM) & 32.000 \\
2 & Pelumas(oli) & 6.660 \\
3 & Oli hidrolik & 400 \\
4 & Gemuk/gress & 14.960 \\
5 & Operator & 20.000 \\
6 & Pemeliharaan dan perawatan alat & 17.278 \\
7 & Pemeliharaan dan perawatan ban & 3.600 \\
\hline \multicolumn{2}{|c|}{ Biaya pengoperasian per jam } & 94.898 \\
\hline
\end{tabular}

Sumber : Analisis Biaya Pengoperasian Alat

Tabel 26 Rekapitulasi Biaya Penggunaan Alat Berat

\begin{tabular}{|c|c|c|c|c|}
\hline Alat berat & $\begin{array}{c}\text { Alat yang } \\
\text { digunakan }\end{array}$ & $\begin{array}{c}\text { Waktu kerja } \\
\text { (jam) }\end{array}$ & Biaya perjam (Rp) & $\begin{array}{c}\text { Biya } \\
\text { pengoperasian } \\
\text { alat (Rp) }\end{array}$ \\
\hline 1 Unit & Excavator & 26 & 307.895 & 8.005 .270 \\
3 Unit & Dump Truck & 87.7 & 94.898 & 8.322 .554 \\
\hline
\end{tabular}

Sumber : Analisis Biaya Pengoperasian Alat

\section{HASIL}

A. Metode Pelaksanaan Kegiatan dan Perhitungan Kapasitas Produksi Alat Berat.

Pekerjaan Galian

a. Data lapangan
1) Volume galian $=453.2 \mathrm{~m}^{3}$
2) Jenis tanah = Tanah Biasa
3) Panjang Galian $=1.430,4 \mathrm{~m}$
4) Lebar Galian $\quad=1.20 \mathrm{~m}$
5) Kedalaman galian $=0.12 \mathrm{~m}$ 
b. Metode pelaksanaan pekerjaan

Tanah yang digali menggunakan excavator dengan ukuran dan kedalaman sesuai petunjuk direksi pekerjaan. Hasil galian diangkut ke tempat yang telah ditentukan menggunakan dump truck.

c. Alat yang digunakan

1) Excavator PC 200 (Komatsu)

Produksi persiklus (q)

$\mathrm{q}=\mathrm{q} 1 \times \mathrm{k}$

$$
=0.9 \times 0.8=0.72 \mathrm{M}^{3}
$$

Waktu siklus (Cms)

$\mathrm{Cms}=$ waktu gali + waktu putar $\mathrm{x} 2+$ waktu buang

$$
\begin{aligned}
& =32+(7 \times 2)+8 \\
& =54 \text { detik }
\end{aligned}
$$

Produksi alat perjam $(\mathrm{Q})$

$$
\begin{aligned}
Q & =\frac{0.72 \times 3600 \times 0,38}{54} \\
& =\frac{984,96}{54}=17,58 \mathrm{~m}^{3}
\end{aligned}
$$

Produksi excavator diperoleh hasil sebesar $17,58 \mathrm{~m}^{3}$

2) Dump truck (Mitsubishi)

Waktu siklus (Cmt)
a) Waktu muat$$
=\mathrm{n} \times \mathrm{Cms}
$$

$\mathrm{n}=$ jumlah siklus yang diperlukan untuk mengisi dump truck

$$
\begin{array}{ll}
\mathrm{n} & =\frac{\text { Kapasitas Dump truck }}{\text { Kapasitas Bucket excavator } \mathrm{x} \text { Faktor bucket }} \\
\mathrm{n} & =\frac{4}{0.9 \times 0,8}=3.55
\end{array}
$$

$\mathrm{Cms}=54$ detik $(0,9$ menit $)$

Waktu muat $=\mathrm{n} \times \mathrm{Cms}$

$$
\begin{aligned}
& =3,55 \times 0,9 \\
& =3,19 \text { menit }
\end{aligned}
$$

b) Waktu buang dan waktu kembali

Jarak angkut rata-rata (D) $=2,0 \mathrm{~km}$

Kecepatan bermuatan (V1) $=30 \mathrm{~km} / \mathrm{jam}$

Kecepatan kosong (V2) $\quad=50 \mathrm{~km} / \mathrm{jam}$

Bermuatan $=\frac{\mathrm{D}}{\mathrm{V} 1}=\frac{2}{30}=0,067$ jam (4,02 menit)

Kosong $\quad=\frac{\mathrm{D}}{\mathrm{V} 2}=\frac{2}{50}=0,04$ jam $(2,4$ menit $)$

c) Waktu dumping/buang (t1) $=1,25$ menit

d) Waktu tunggu ( $\mathrm{t} 2) \quad=0.30$ menit

e) Waktu siklus excavator $=0.9$ menit

Jadi waktu siklus dump truck (cmt)

$$
\begin{aligned}
\mathrm{Cmt} & =(\mathrm{n} \cdot \mathrm{Cms})+\frac{\mathrm{D}}{\mathrm{VI}}+\mathrm{t} 1+\frac{\mathrm{D}}{\mathrm{V} 2}+\mathrm{t} 2 \\
& =(3,55 \cdot 0,9)+\frac{2}{30}+1,10+\frac{2}{50}+0,30 \\
& =(3,195)+4,02+1,10+2,4+0,30 \\
& =9,74 \text { menit }
\end{aligned}
$$

Perkiraan jumlah dump truck yang dibutuhkan

$$
\begin{aligned}
\mathbf{M} & =\frac{\text { Waktu siklus dump truck }}{\text { Waktu muat }} \\
& =\frac{9,74 \text { menit }}{3,19}=3,05 \approx 3
\end{aligned}
$$

Produksi Dump Truk per jam 


$$
\begin{aligned}
\mathrm{C} & =\text { Produksi persiklus }=\mathrm{n} . \mathrm{ql} \times \mathrm{K} \\
& =3,55 \times 0,9 \times 0,8 \\
& =2,56 \mathrm{~m}^{3} \\
\mathrm{P} & =\frac{\mathrm{C} \times 60 \times \mathrm{FK}}{\mathrm{Cmt}}\left(\mathrm{m}^{3} / \mathrm{jam}\right) \\
& =\frac{2,56 \times 60 \times 0,41}{9,74} \\
& =\frac{62,976}{9,74}=6,46 \mathrm{~m}^{3}
\end{aligned}
$$

Produksi setiap truk diperoleh hasil sebesar $6,46 \mathrm{~m}^{3}$

Tabel 20 Waktu Siklus

\begin{tabular}{|c|c|c|c|c|c|}
\hline No & Jenis Alat & $\begin{array}{c}\text { Waktu } \\
\text { Gali }\end{array}$ & Waktu Putar & $\begin{array}{c}\text { Waktu } \\
\text { Buang }\end{array}$ & $\begin{array}{c}\text { Waktu Siklus } \\
\text { (Detik) }\end{array}$ \\
\hline 1 & Excavator & 32 & 14 & 8 & 54 \\
\hline
\end{tabular}

Sumber : Data lapangan

\begin{tabular}{|r|l|l|l|l|l|l|}
\hline No & Jenis Alat & $\begin{array}{l}\text { Waktu } \\
\text { Pengisian }\end{array}$ & $\begin{array}{c}\text { Waktu } \\
\text { Mengangkut }\end{array}$ & $\begin{array}{c}\text { Waktu } \\
\text { Kembali }\end{array}$ & ktu Buang & $\begin{array}{l}\text { Waktu } \\
\text { Tunggu }\end{array}$ \\
\hline 1 & Dump Truk & 3,55 & 3,19 & 2,4 & 1,25 & 0,30 \\
\hline
\end{tabular}

Sumber : Data lapangan

\section{KESIMPULAN}

1. Analisa produksi alat berat dengan menggunakan alat berat excavator komatsu PC 200 pada proyek jalan ruas sumberjo-pelitakan diperoleh total volume galian tanah sebesar $453.2 \mathrm{~m}^{3}$, Hasil analisa perhitungan produksi alat berat excavator diperoleh 17,58 $\mathrm{m}^{3} /$ per-jam, dengan produksi per-siklus sebesar $0,72 \mathrm{~m}^{3}$, dan waktu siklus digunakan satu putaran selama 54 detik. Sedangkan volume galian tanah yang terbesar pada pekerjaan galian sebesar $79,1 \mathrm{~m}^{3}$, volume galian tanah terkecil sebesar $42.5 \mathrm{~m}^{3}$. Alat berat dump truck diperoleh siklus 9,74 menit dengan persiklus sebanyak $2,56 \mathrm{~m}^{3}$ dengan produksi perjam sebanyak $6,46 \mathrm{~m}^{3}$.

2. Biaya pengoperasian alat berat excavator selama pengerjaan galian tanah sebesar $\mathrm{Rp}$ 8.005.270 sedangkan untuk penggunaan alat berat Dump truck yang digunakan untuk mengangkut material dari hasil penggalian dari alat berat excavator dengan produksi alat berat dump truck sebanyak $6,46 \mathrm{~m}^{3}$, biaya pengoperasian alat berat dump truck selama alat beroperasi adalah sebesar Rp. 8.322.554.

\section{DAFTAR PUSTAKA}

Adatika Lisa. 2006, Manajemen Alat Berat Pada Pekerjaan Tanah Proyek Pembangunan Jalan AP-10 Batang-Waleri(III) Jateng. (Tugas Akhir).

Asiyanto. 2008. Manajemen Alat Berat Untuk Konstruksi. PT. Pradnya Paramita. Jakart.

Dwi, Novi Setiawati. 2013. Analisis produktifitas alat berat pada proyek pembangunan pabrik krakatau posco zone IV di cilegon.

Gustiono, Andri. 2010. Analisa Biaya Penggunaan Alat Berat. (Jurnal)

Kelvin, Rudy Sutanto . 2013. produktifitas alat berat pada pekerjaan galian gedung P1 P2 UK petra.

Mangerangi, Kamaruddin. 2003. Analisa produksi dan biaya penggunaan alat-alat berat untuk pekerjaan tanah pada proyek bending bissua kabupaten gowa.

Novianti Ayu A.. 2017. Analisa kapasitas produksi alat berat di area lahan parkirgedung direktorat politeknik negeri Balikpapan. 
Rochmanhadi, Ir. Alat-alat Berat dan Penggunaannya.

Rochmanhadi, Ir. Kapasitas dan Produksi Alat Berat, Departemen Pekerjaan Umum.

Rochmanhadi, Ir. Perhitungan Biaya pelaksanaan Pekerjaan dengan Menggunakan Alatalat berat.

Rostiyanti, Fatena Susi. 2008 . Alat Berat Untuk Proyek Konstruksi Edisi revisi Kedua. Rineka Cipta.Jakarta

Wilopo, Djoko.2009. Metode Konstruksi dan Alat-Alat Berat. UI Press. Jakarta.

Z.A, Fikri. 2016. Analisis kapasitas produksi excavator pada proyek perumahan cibubur. 